\title{
Perpendicularly aligned, anion conducting nanochannels in block copolymer electrolyte films
}

Christopher G. Arges ${ }^{a, b}$, Yu Kambe $e^{a, b}$, Hyo Seon Suh ${ }^{a, b}$, Leonidas E. Ocola ${ }^{c, d}$, and Paul F. Nealey ${ }^{a, b}$

${ }^{a}$ Institute for Molecular Engineering, University of Chicago, 5735 S. Ellis Ave., Chicago, IL 60637

${ }^{b}$ Materials Science Division, Argonne National Laboratory, 9700 S. Cass Ave., Lemont, IL 60439

${ }^{c}$ Center for Nanoscale Materials, Argonne National Laboratory, 9700 S. Cass Ave., Lemont, IL 60439

${ }^{\mathrm{d} U n i v e r s i t y ~ o f ~ C h i c a g o ~ M R S E C, ~ C h i c a g o ~ M a t e r i a l s ~ R e s e a r c h ~ C e n t e r, ~} 929$ E. 57th St., Chicago, IL 60637

\section{Electronic Supporting Information}


a.)

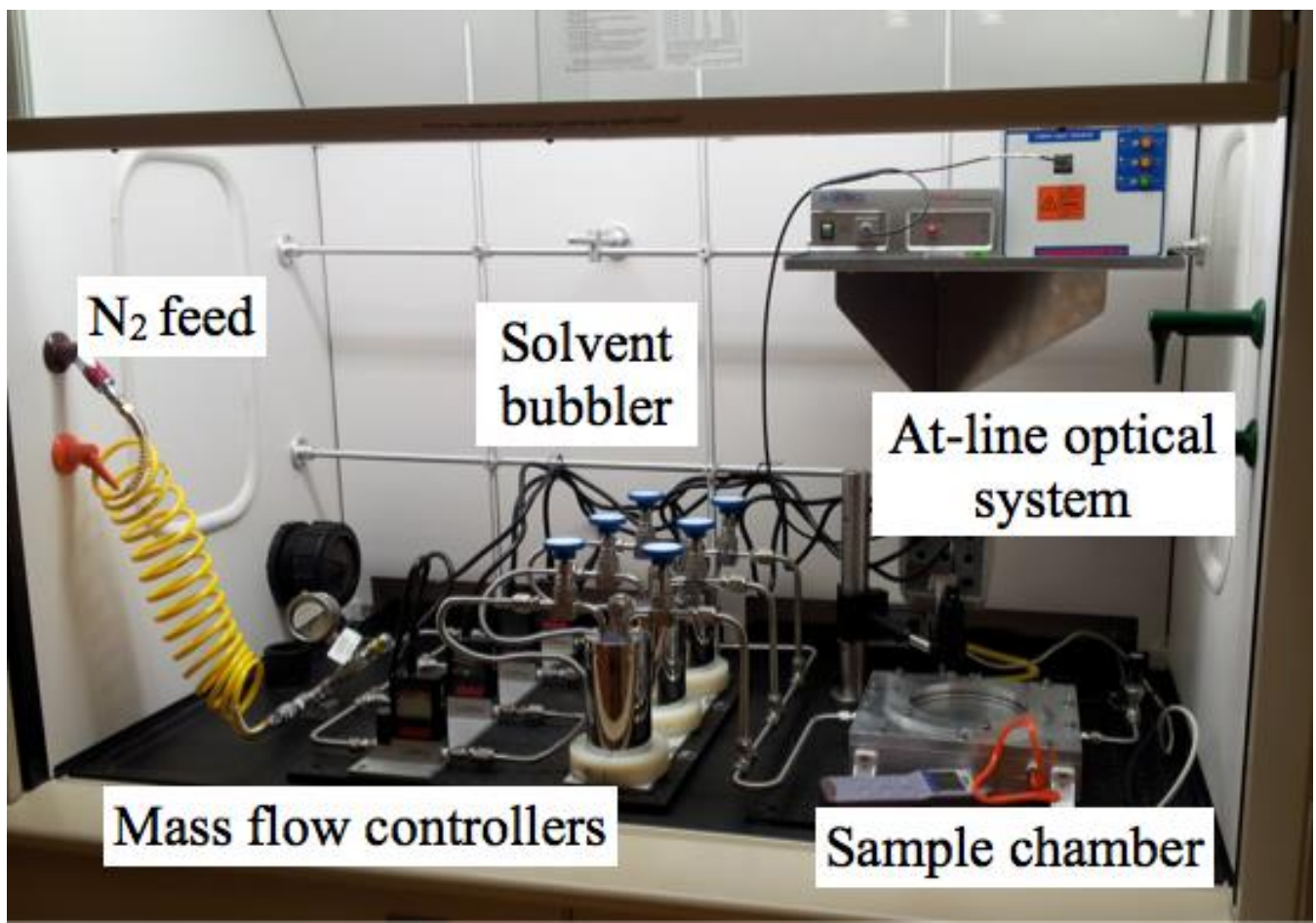

b.)

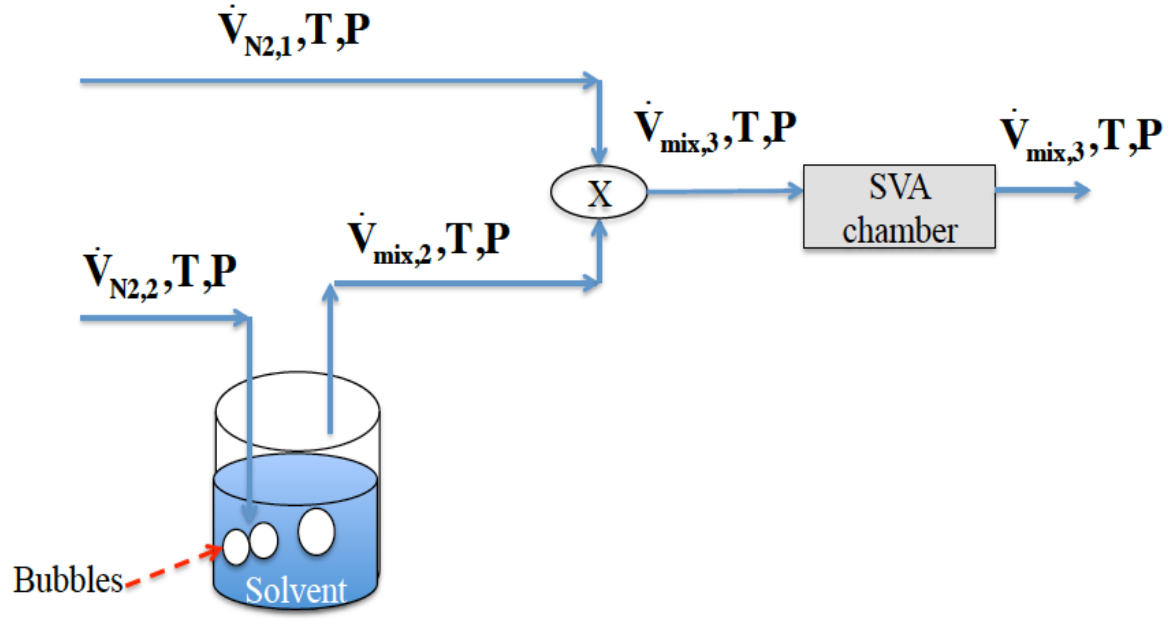

Figure S1. a.) Picture of the solvent vapor annealing flow chamber. Above the sample chamber, an at-line Filmetrics optical detector is positioned to monitor film thickness during solvent vapor annealing. b.) A process flow diagram of the solvent vapor annealing flow chamber. Computer controlled flow controllers set the volumetric flow rates of the nitrogen carrier and dilution gases. 


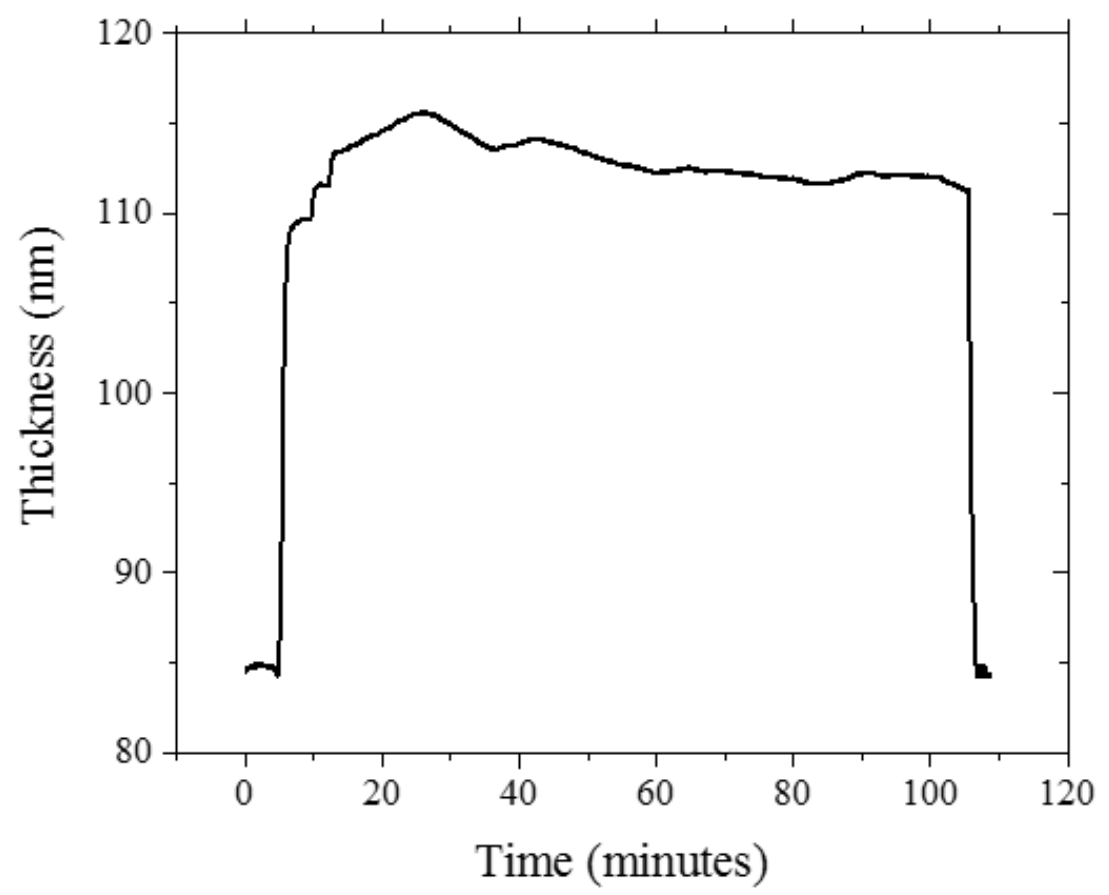

Figure S2. Film thickness of a polystyrene reference film versus time for a solvent vapor annealing run

A polystyrene reference film of $85 \mathrm{~nm}$ was prepared to monitor film swelling during solvent vapor annealing. We monitor the film swelling as a means to verify that the corresponding operating parameters (flow rate, temperature, and back pressure) yield the same film swelling from run to run. It is also important to point out that we have established that the swelling of polystyrene and poly(2-vinyl pyridine) films in the presence of acetone vapor is the same. This was expected because the acetone vapor induces a neutral boundary condition at the free surface interface during annealing.

The mathematical relationship between polymer film thickness swelling and the partial pressure of solvent in the flow chamber can be derived through classical thermodynamics for a quasi-static process. ${ }^{1}$ The relevant equations are listed below.

$\ln \left(\frac{P_{S, C}}{P^{o}}\right)=\chi_{S-p}\left(\frac{1}{S R^{2}}\right)+\ln \left(1-\frac{1}{S R}\right)+\left(1-\frac{1}{r_{p}}\right) \frac{1}{S R}$

Relationship of the partial pressure of the solvent in the flow chamber to the swelling ratio of polymer 
$P_{S, C}=\frac{P_{S}^{s a t} \dot{V}_{N 2,2}}{\left(\dot{V}_{N 2,1}+\dot{V}_{N 2,2}\right)}$

Partial pressure of solvent in the solvent vapor annealing chamber

$S R=\frac{D}{D_{o}}=\frac{1}{\Phi_{P}}$

The swelling ratio of film (due to solvent uptake)

$\mu_{s}^{p-s}=\left(\frac{\partial G^{p-s}}{\partial n_{s}}\right)_{T, P}$

The definition of the chemical potential of solvent in the solvent-polymer mixture

$G^{p-s}=n_{s} G_{s}^{\text {pure }}+n_{p} G_{p}^{\text {pure }}+\Delta G_{\text {mix }}^{p-s}$

$\Delta G_{m i x}^{p-s}=R T\left(n_{s} \ln \Phi_{s}+n_{p} \ln \Phi_{p}+n_{s} \Phi_{p} \chi_{s-p}(T)\right)$

The Gibbs Free Energy expression for the polymer-solvent mixture. The delta G value of mixing derived from Flory-Huggins Theory.

\begin{tabular}{|c|c|}
\hline $\begin{array}{l}\mathrm{n}_{\mathrm{p}} \text { : moles of polymer chains in the } \\
\text { polymer-solvent mixture }\end{array}$ & $\begin{array}{l}G^{p-s}: \text { Gibbs free energy of the polymer- } \\
\text { solvent mixture }\end{array}$ \\
\hline$\mu_{s}^{\text {pure }}$ : chemical potential of pure solvent & $\mu_{p}^{\text {pure }}$ : chemical potential of pure polymer \\
\hline $\begin{array}{l}\Delta G_{m i x}^{p-s} \text { : Change in Gibbs free energy of } \\
\text { mixing for a polymer-solvent mixture }\end{array}$ & $\begin{array}{l}\mu_{s}^{p-s}: \text { chemical potential of the solvent in } \\
\text { the polymer-solvent mixture }\end{array}$ \\
\hline $\begin{array}{l}\text { D: film thickness during solvent vapor } \\
\text { annealing }\end{array}$ & $\begin{array}{l}\mathrm{D}_{\mathrm{o}} \text { : film thickness of the polymer film } \\
\text { without solvent }\end{array}$ \\
\hline SR: swelling ratio & $\begin{array}{l}\Phi_{p}: \text { volume fraction of polymer in the } \\
\text { polymer-solvent mixture }\end{array}$ \\
\hline $\begin{array}{l}\chi_{s-p}: \text { Flory-Huggins interaction parameter } \\
\text { describing the enthalpic interaction } \\
\text { between solvent and polymer }\end{array}$ & T: temperature \\
\hline $\begin{array}{l}\mathrm{r}_{\mathrm{p}}: \text { degree of polymerization }- \text { number of } \\
\text { monomer units in a chain }\end{array}$ & $\begin{array}{l}P_{s, c}: \text { partial pressure of the solvent in the } \\
\text { sample chamber }\end{array}$ \\
\hline $\begin{array}{l}P_{s}^{s a t} \text { : saturated vapor pressure of the } \\
\text { solvent at a given temperature }- \text { determined } \\
\text { from experimental data or Antoine } \\
\text { equation }\end{array}$ & R: gas constant \\
\hline
\end{tabular}




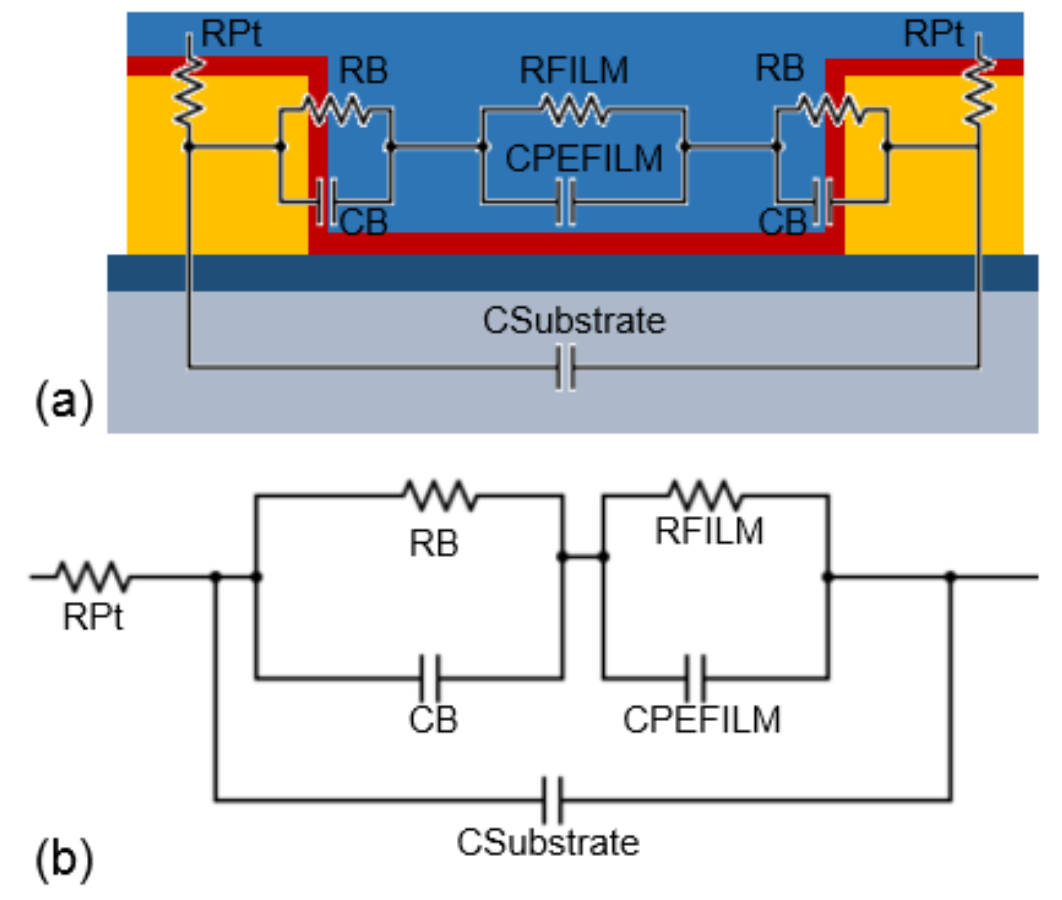

Figure S3. a.) Cross sectional diagram of the teeth in the interdigitated electrodes and b.) the equivalent circuit model that was used for the modeling of the system. 


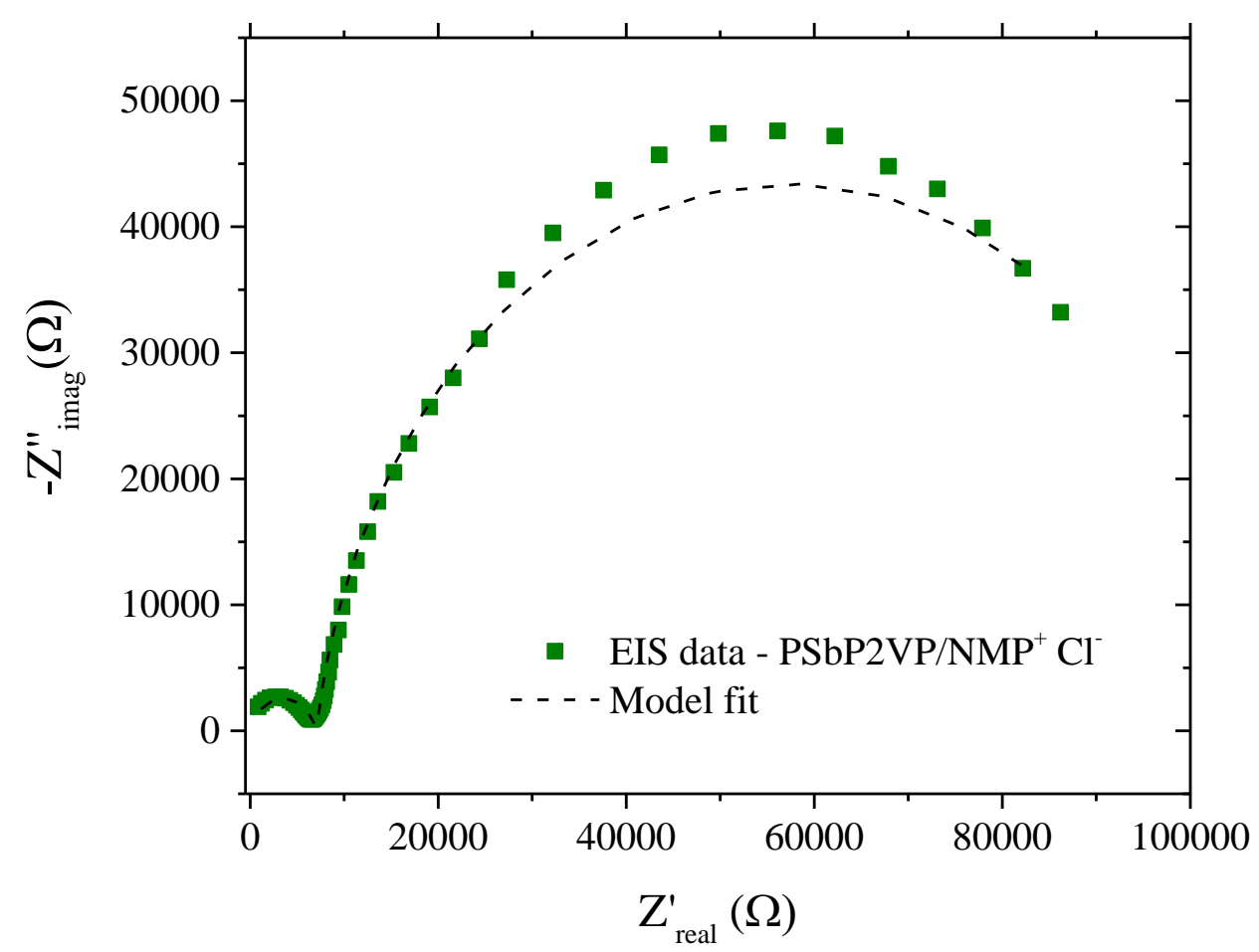

Figure S4. Representative model fit of the equivalent circuit model for the $\mathrm{PS} b \mathrm{P} 2 \mathrm{VP} / \mathrm{NMP}^{+} \mathrm{Cl}^{-}$block copolymer electrolyte with 48 hours exposure to methyliodide vapor.

To extract the BCE film resistance (RFILM) from the galvanostatic EIS measurements, an equivalent circuit design was fitted to the Nyquist plot. Figure S3a shows a cross sectional diagram of the interdigitated electrode (IDE) that depicts the interdigitated electrode with the brush layer and the block copolymer electrolyte film. The equivalent circuit model utilized resistor, capacitor, and constant phase element components.

$Z_{R}=R$

$<7>$

Shows the relationship between resistance and the impedance element where $\mathrm{R}$ is resistance.

$Z_{C}=\frac{1}{i \omega C}$

The relationship between the capacity and the impedance element where $\omega$ is the frequency of the measurement and $i$ is the imaginary number operator.

$Z_{C P E}=\frac{1}{(i \omega C)^{\alpha}}$ 
The $\alpha$ value is assigned a value between 0 and 1 and accounts for the ideality of the capacitor.

In the model given above, the BCE path was modeled as a resistor and a capacitor in parallel connected in series to another resistor and capacitor in parallel. The two parallel elements were models for the polymer electrolyte brush and the BCE. The two elements were in series because the charge carrier inevitably crosses through the brush prior to passing through the BCE. This sequence is effectively represented in a Nyquist plot as two semi-circles of varying radii. The employed equivalent circuit model is shown in Figure S3b.

The model fit prioritized the smaller semi-circle in the Nyquist plot when fitting because that semi-circle represented the BCE film resistance in the system. The model was designed and fitted using the SimpleX damped least squares method available on the ECHEM analysis tool by Gamry Inc. The optimization of the fit on average took 20 iterations. The extracted resistance was used to calculate the ionic conductivity - see equation $\langle 10\rangle$.

$\sigma_{f i l m}=\frac{1}{R_{f i l m}} \cdot \frac{d}{l(n-1) t}$

The film ionic conductivity $\left(\sigma_{\text {film }}\right)$ was calculated with the modeled film resistivity $\left(R_{\text {film }}\right)$, the spacing between the interdigitated electrode teeth $(\mathrm{d}=100 \mu \mathrm{m})$, the length of the teeth $(1=0.45 \mathrm{~cm})$, thickness of the BCE film $(\mathrm{t}=28 \mathrm{~nm})$ and the number of electrodes $(\mathrm{N}=22)$. Paul et al. also used equation $\langle 10\rangle$ to calculate the ionic conductivity of a thin film polymer electrolyte on an interdigitated electrode. ${ }^{2}$

a.)
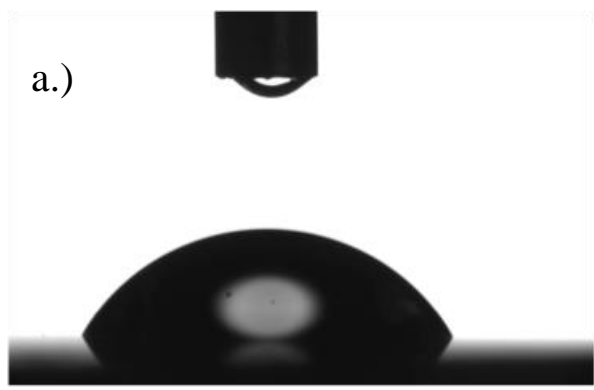

P2VP brush

Water contact angle: $61^{\circ}$ b.)
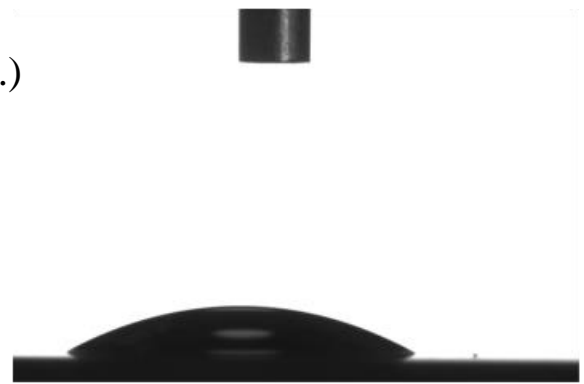

$\mathrm{P} 2 \mathrm{VP} / \mathrm{NMP}^{+} \mathrm{I}^{-}$(24 hr methylation) Water contact angle: $20^{\circ}$

Figure S5. Water contact angle images of a.) P2VP brushes (no methylation) and b.) $\mathrm{P} 2 \mathrm{VP} / \mathrm{NMP}^{+} \mathrm{I}^{-}$after 24 hour exposure to methyliodide vapor. 


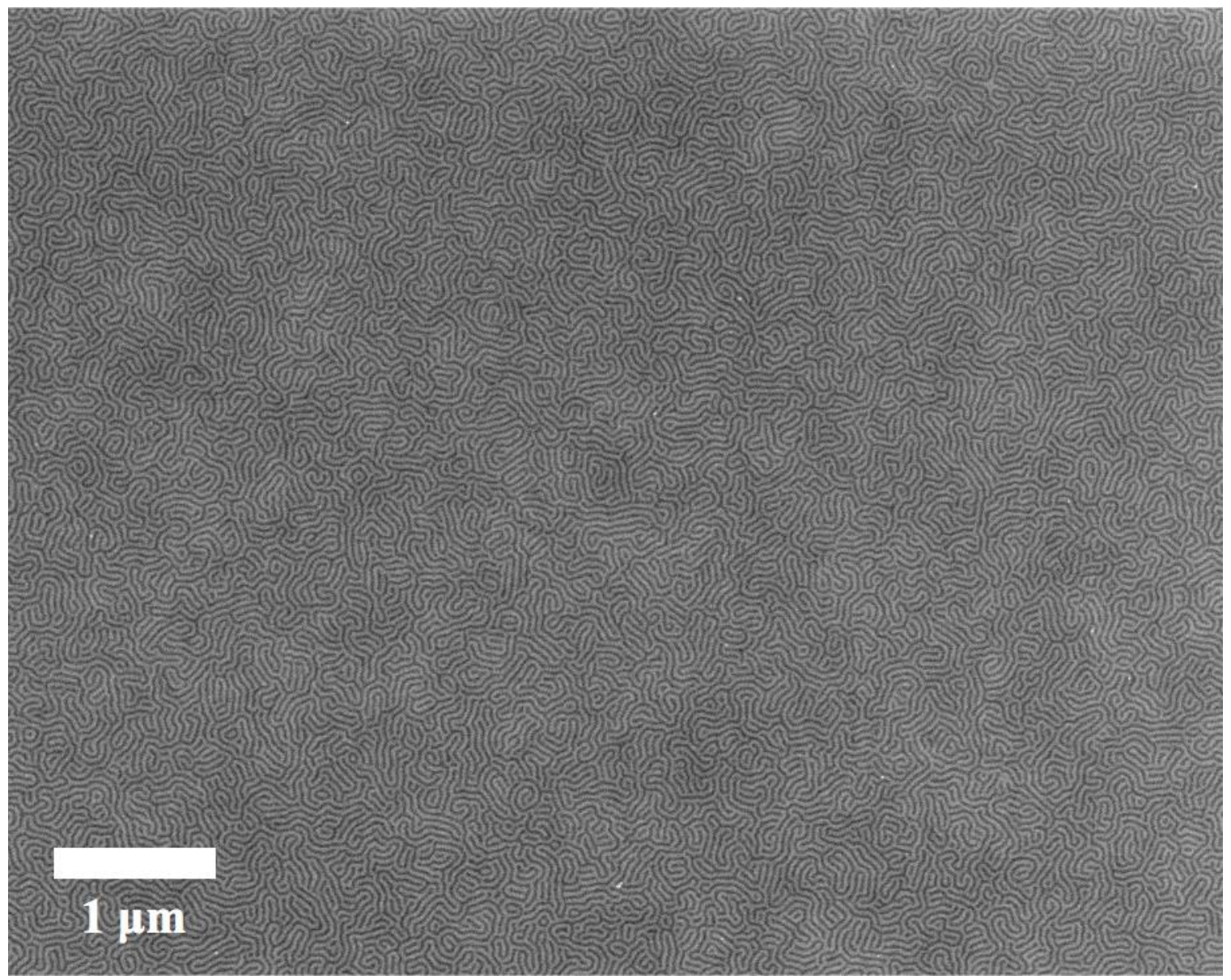

Figure S6. SEM image of fingerprint lamellae of PS $b$ P2VP (no methylation). Area size over $42 \mu \mathrm{m}^{2}$. 


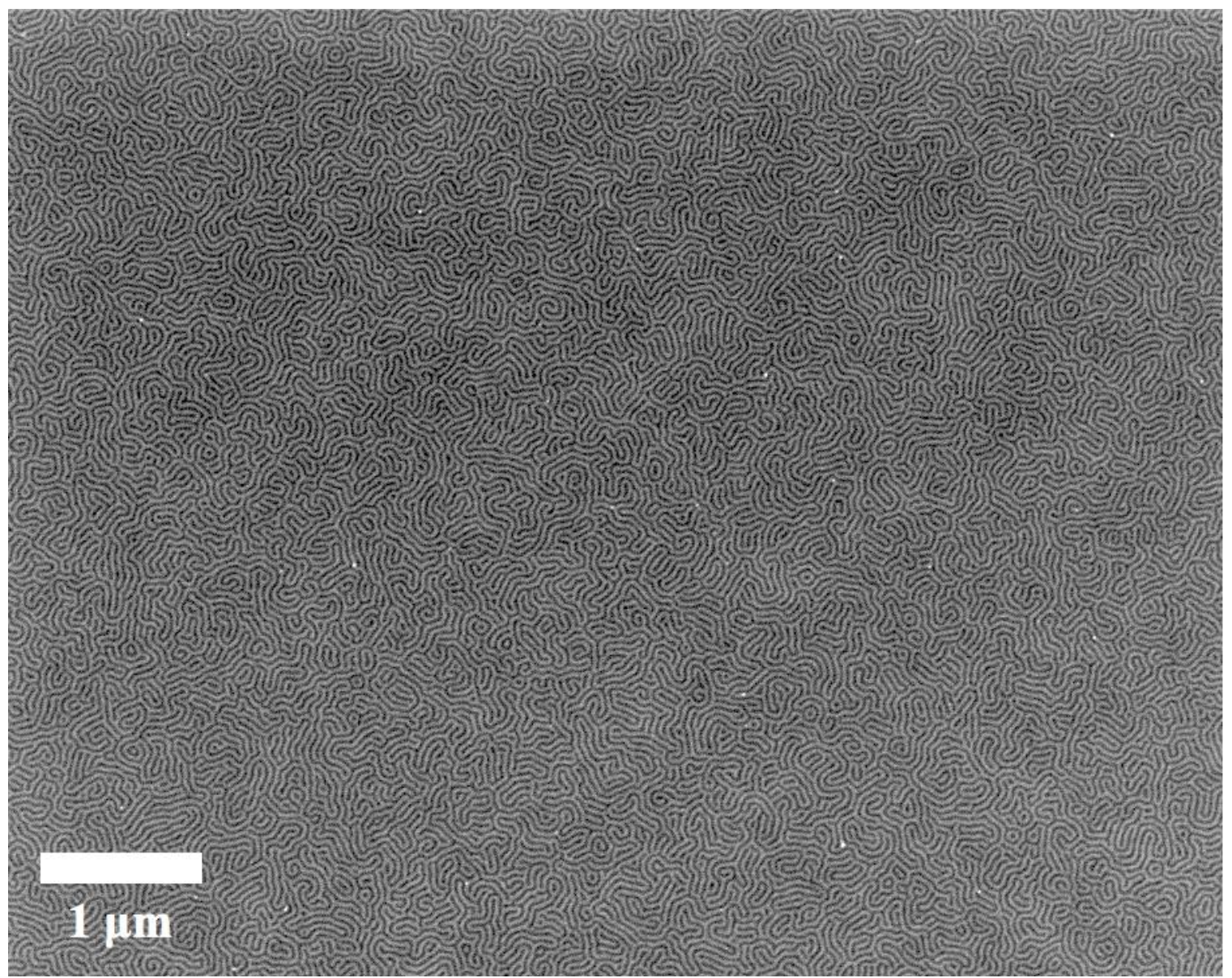

Figure S7. SEM image of fingerprint lamellae of PS $b$ P2VP/NMP ${ }^{+} \mathrm{I}^{-}$(methylated for 2 hours). Area size over $42 \mu \mathrm{m}^{2}$. 


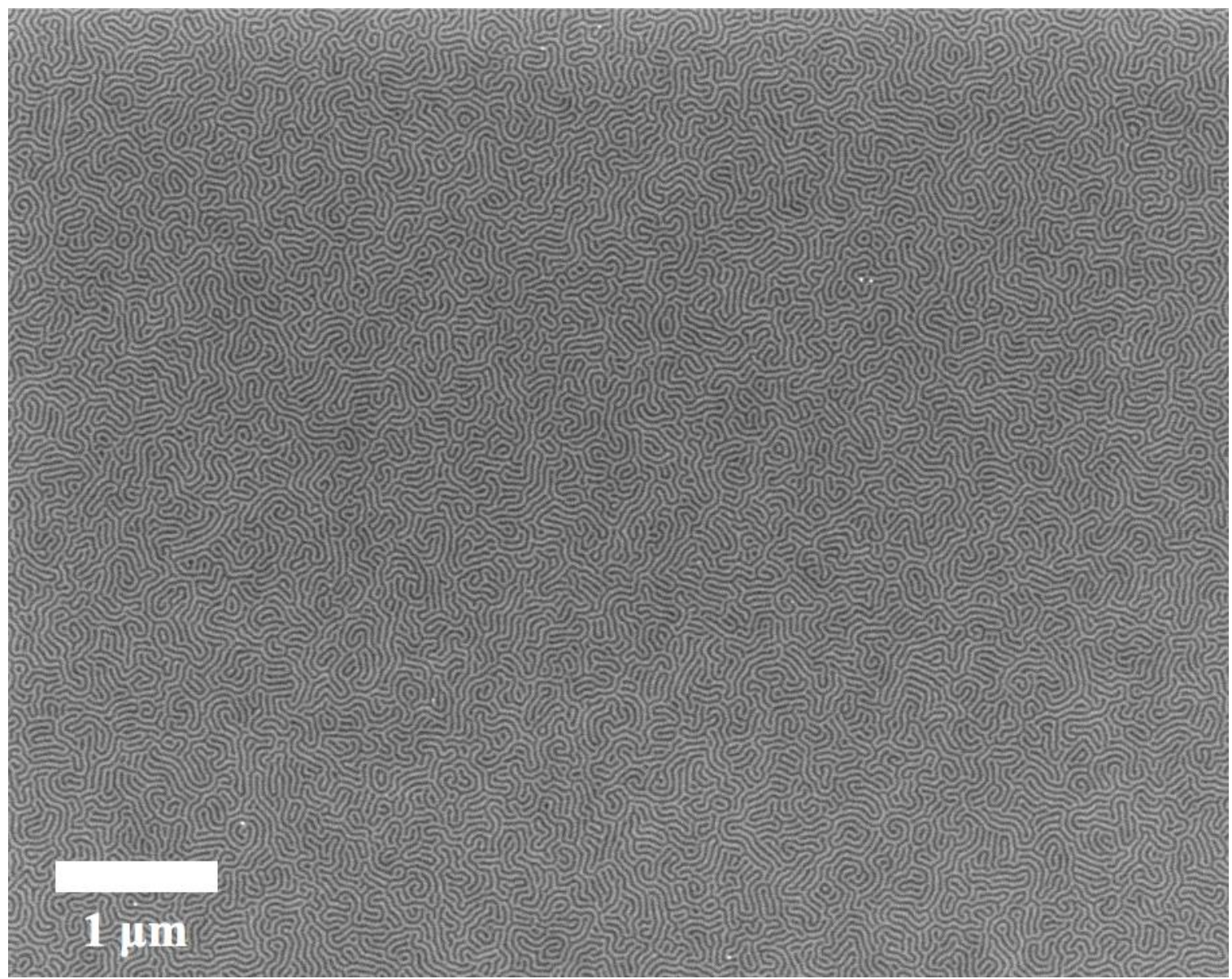

Figure S8. SEM image of fingerprint lamellae of PS $b \mathrm{P} 2 \mathrm{VP} / \mathrm{NMP}^{+} \mathrm{I}^{-}$(methylated for 4 hours). Area size over $42 \mu \mathrm{m}^{2}$. 


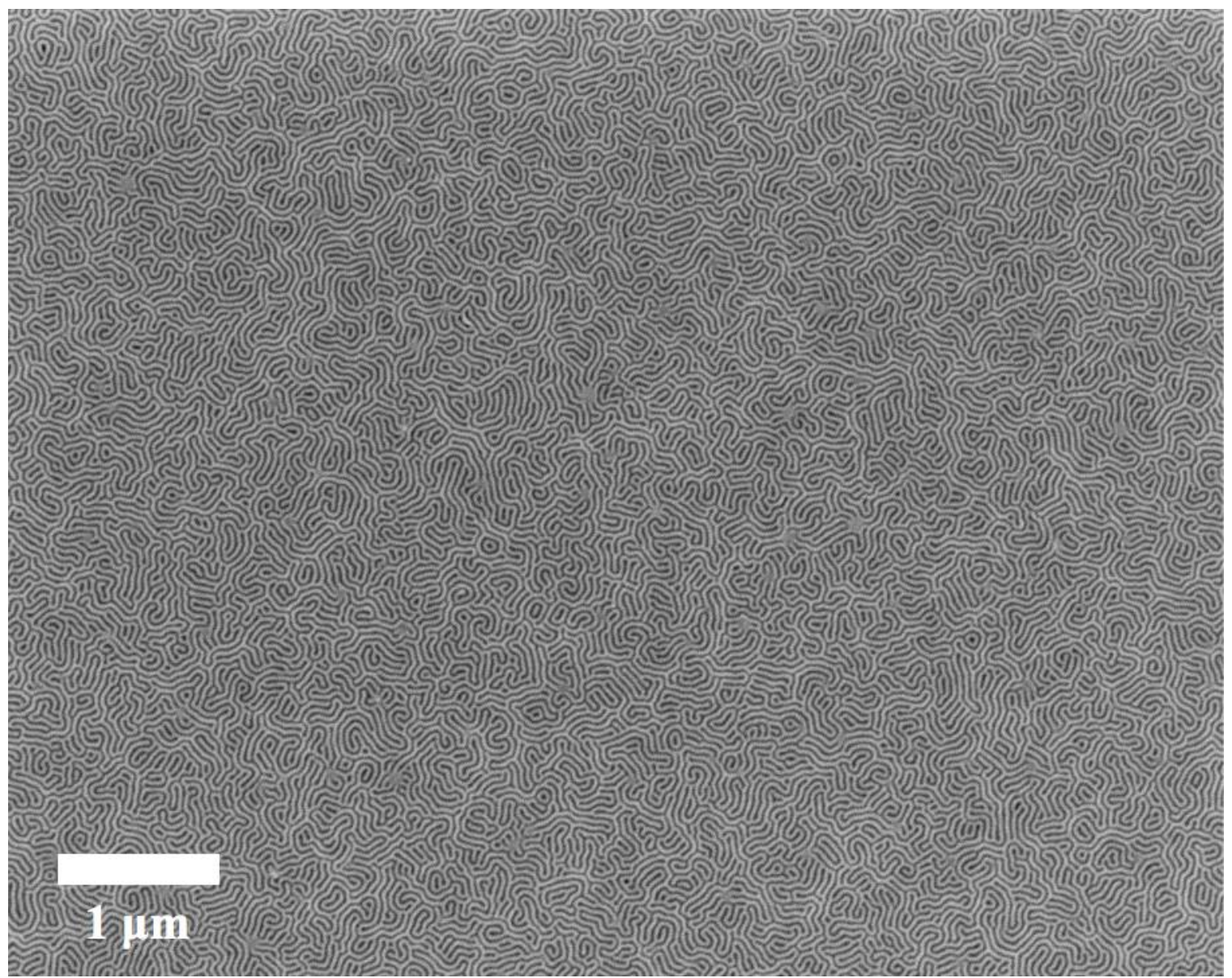

Figure S9. SEM image of fingerprint lamellae of PS $b \mathrm{P} 2 \mathrm{VP} / \mathrm{NMP}^{+} \mathrm{I}^{-}$(methylated for 24 hours). Area size over $42 \mu \mathrm{m}^{2}$. 

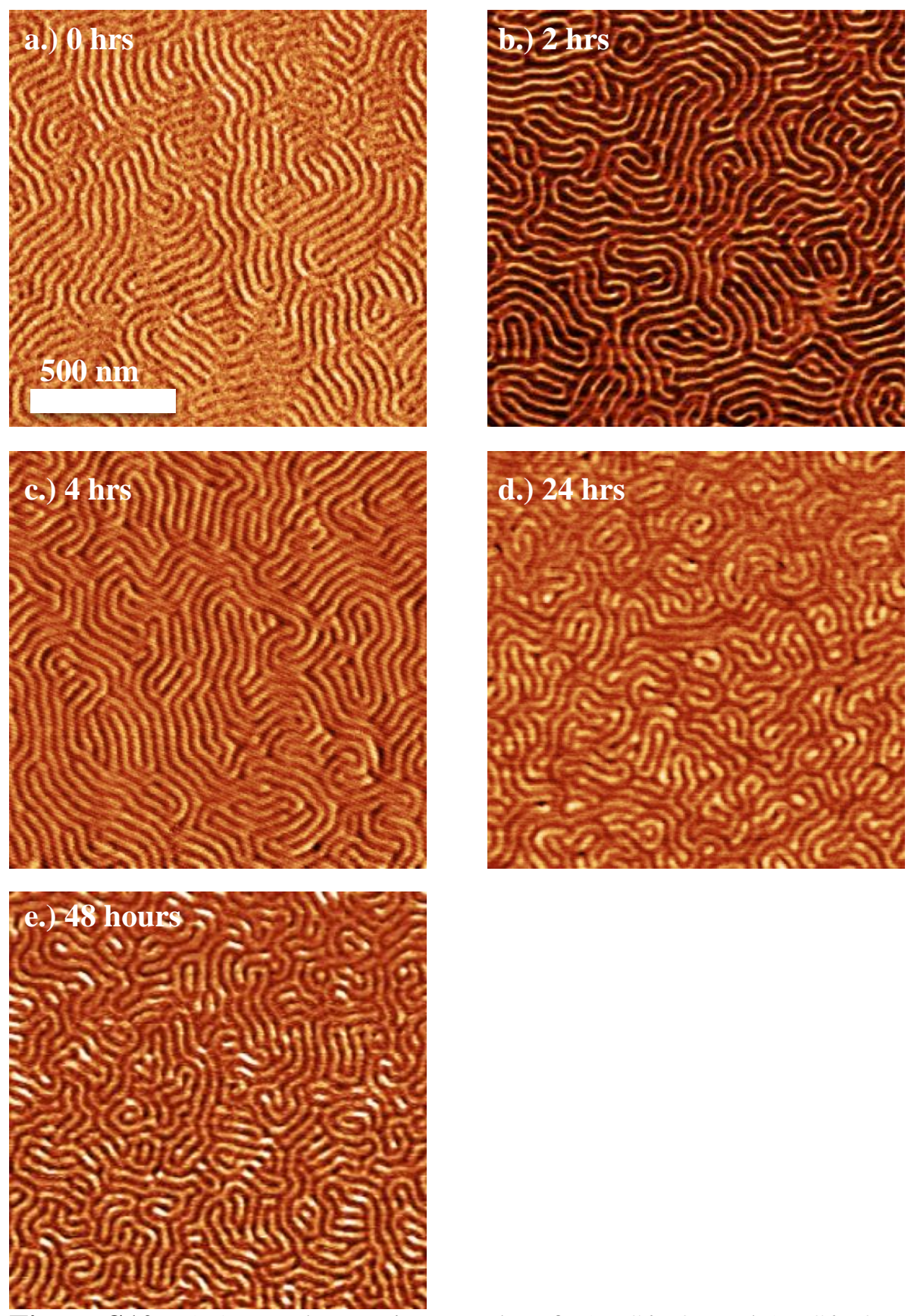

Figure S10. a.) AFM phase micrographs of a.) PS $b \mathrm{P} 2 \mathrm{VP}$, b.) PS $b \mathrm{P} 2 \mathrm{VP} / \mathrm{NMP}^{+} \mathrm{I}^{-}$ (methylated for 2 hours), c.) PS $b \mathrm{P} 2 \mathrm{VP} / \mathrm{NMP}^{+} \mathrm{I}^{-}$(methylated for 4 hours), d.) $\mathrm{PS} b \mathrm{P} 2 \mathrm{VP} / \mathrm{NMP}^{+} \mathrm{I}^{-}$(methylated for 24 hours), and e.) PS $b \mathrm{P} 2 \mathrm{VP} / \mathrm{NMP}^{+} \mathrm{I}^{-}$(methylated for 48 hours). Scale bar $(500 \mathrm{~nm})$ is located in a.). The brighter features in the AFM micrographs belong to the $\mathrm{P} 2 \mathrm{VP} / \mathrm{NMP}^{+} \mathrm{I}^{-}$domain. 

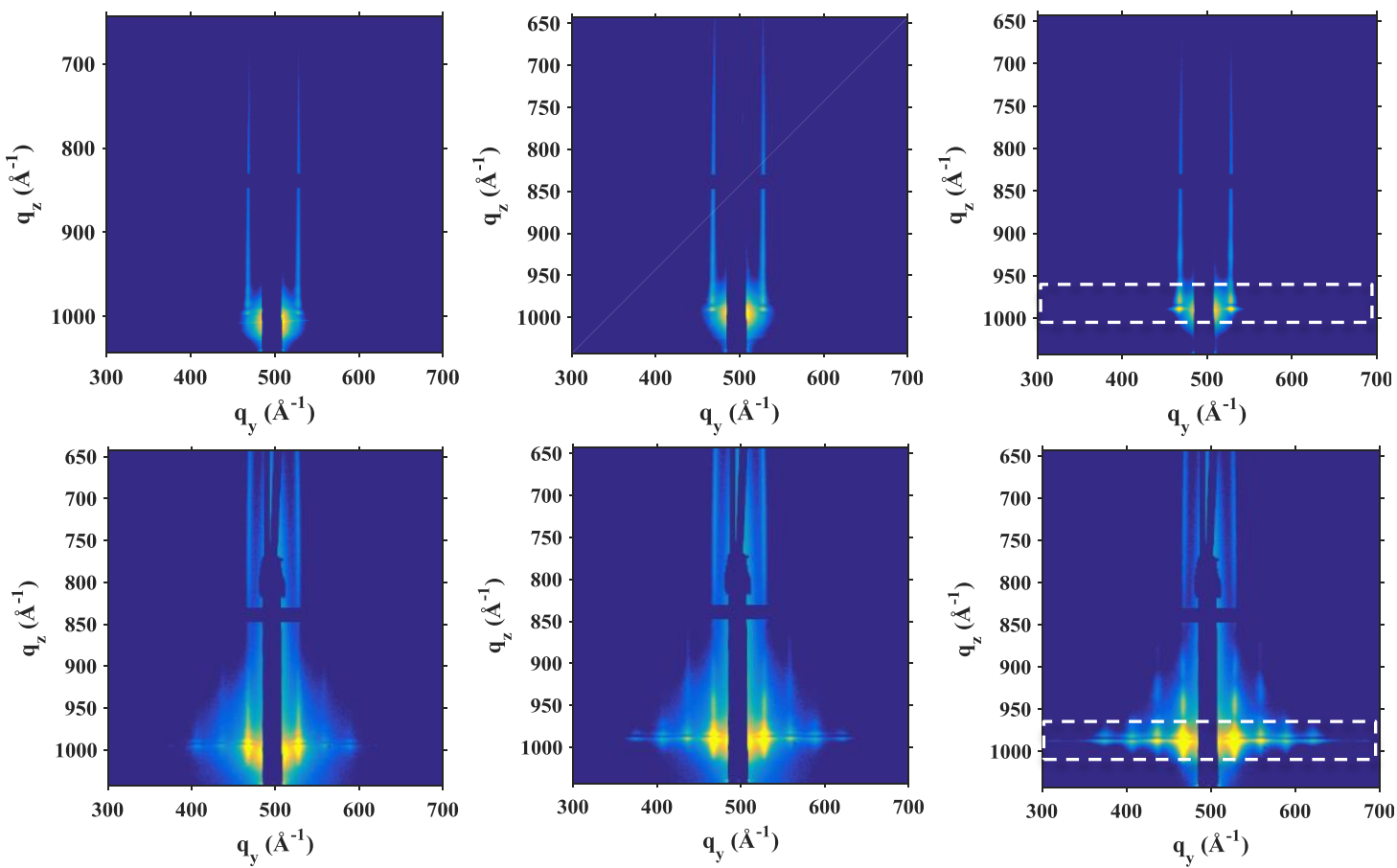

Figure S11. GISAXS data pre (top) and post (bottom) CVIR with incident angles from 0.14 (left) 0.18 (middle) to 0.20 (right). Horizontal line cut of the Yoneda peak is shown by the dotted line. 


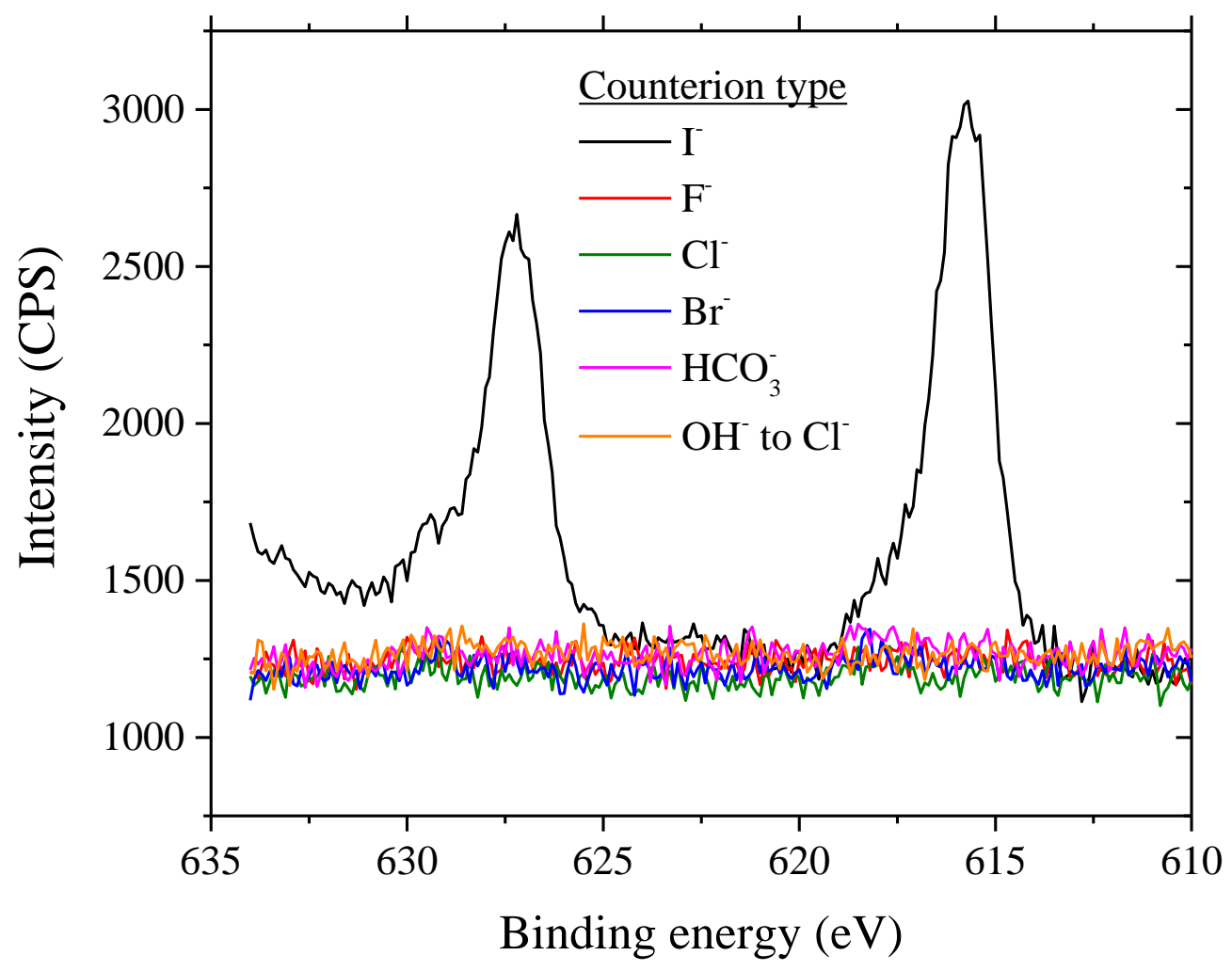

Figure S12. XPS I 3d spectra of PS $b \mathrm{P} 2 \mathrm{VP} / \mathrm{NMP}^{+}$(exposed to methyliodide vapor for 48 hours) a.) before ion-exchange and after ion-exchange to the $\mathrm{F}^{-}$form (b.), $\mathrm{Cl}^{-}$form (c.), $\mathrm{Br}^{-}$(d.), $\mathrm{HCO}_{3}^{-}$(e.), and $\mathrm{OH}^{-}$to $\mathrm{Cl}^{-}$(f). 


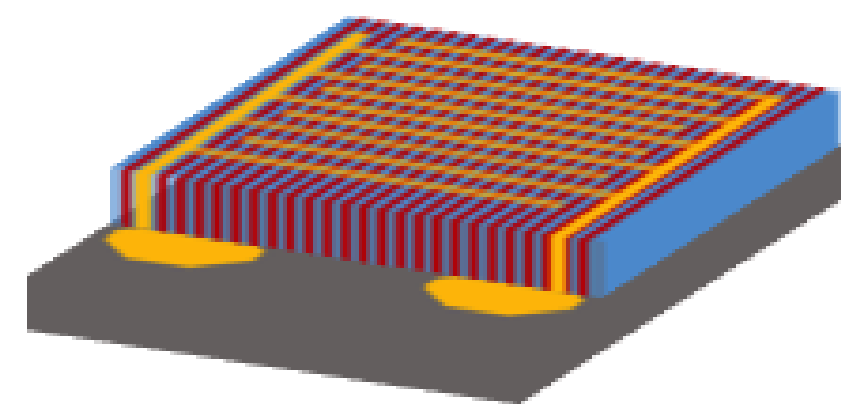

Figure S13. Conceptual image of straight-line lamellae block copolymer electrolyte integrated into an interdigitated electrode substrate.

\section{References}

1. de Pablo, J. J.; Schieber, J. D., Molecular Engineering Thermodynamics. Cambridge: 2014.

2. Paul, D. K.; McCreery, R.; Karan, K., Proton Transport Property in Supported Nafion Nanothin Films by Electrochemical Impedance Spectroscopy. J. Electrochem. Soc. 2014, 161, F1395-F1402. 